\title{
Levels of Adipokines and Some Steroids During the Menstrual Cycle
}

\author{
M. ŠRÁMKOVÁ ${ }^{1,2}$, M. DUŠKOVÁ ${ }^{1}$, J. VÍTKÜ ${ }^{1}$, J. VČELÁK ${ }^{1}$, P. MATUCHA ${ }^{1}$, \\ O. BRADNOVÁ ${ }^{1}$, J. DE CORDEIRO ${ }^{2}$, L. STÁRKA ${ }^{1}$ \\ ${ }^{1}$ Institute of Endocrinology, Prague, Czech Republic, ${ }^{2}$ First Medical Faculty, Charles University, \\ Prague, Czech Republic
}

Received June 22, 2015

Accepted July 7, 2015

\section{Summary}

The cyclical effects of hormones during the menstrual cycle (MC) are not just responsible for driving ovulation, but also have significant influence on dietary intake and appetite, as well as psychological and behavioral changes. The aim of our study was to describe changes and relationships between the MC and selected steroids, adipokines and food intake-related hormones. Twenty-seven women with regular menstrual cycles were included in the study, and their hormonal spectrum was measured in regular intervals starting from the first day of their cycle. Classical changes in gonadotropins, estrogens and progesterone during the menstrual cycle are accompanied by less striking but significant changes in 17-hydroxyprogesterone and testosterone. No significant changes show dehydroepiandrosterone and its 7-oxygenated metabolites. Adipokines show a tendency to increase during ovulation, while ghrelin and resistin decrease. There is also a remarkable association of sex hormone-binding globulin on the day of the cycle. Our results demonstrate that changes to adipokines during the menstrual cycle are not substantial, but nonetheless can play a role in the changes of food intake described in the literature. Precise descriptions of physiological changes in healthy women are important in helping us understand the significance of the changes accompanying various pathological states.

\section{Key words}

Menstrual cycle • Adipokines • Steroid hormones • SHBG • Food intake related hormones

\section{Corresponding author}

M. Dušková, Institute of Endocrinology, Národní 8, 11694 Prague 1, Czech Republic. E-mail: mduskova@endo.cz

\section{Introduction}

The cyclical effects of hormones during the menstrual cycle (MC) are not just responsible for influencing ovulation, but also have significant influence on dietary intake and appetite (Davidsen et al. 2007). Some studies have described changes in dietary intake during the MC. Increased energy intake and output has been well-documented in thin women during the luteal phase (McNeil and Doucet 2012). The relationships between the menstrual cycle and food intake lead to questions about the role of adipose tissue hormones in food intake. Published results on leptin and resistin are inconsistent, however, with some studies finding changes during the menstrual cycle and others finding no changes. The aim of our study was to describe changes and relationships between the $\mathrm{MC}$ and selected steroids, adipokines, and food intake-related hormones.

Two decades ago, the first adipokine was discovered - leptin (Zhang et al. 1994) - and adipose tissue began to be viewed also as an endocrine organ (Flier 1995). Many other adipokines were subsequently quickly discovered, and were associated with controlling food intake, energy expenditures, sensitivity to insulin, glucose and lipid metabolism, fat distribution, endothelial function, hemostasis, blood pressure, neuroendocrine regulation, immune system reactivity, the onset of inflammation, the development of pathological complications in the cardiovascular system (atherosclerosis, myocardial infarction), and reproductive system function (Bluher and Mantzoros 2015). In the following text, we present the main function of adipokines, which we investigated in our study.

Leptin is a protein composed of 167 amino acids 
that plays a primary role in adaptation of the organism to starvation. It influences the maintenance of energy homeostasis, limits food intake and increases energy expenditure, signaling the amount of fat and nutrient reserves in the organism, and directly inhibits the concentration of intracellular lipids, increases glucose uptake and liver gluconeogenesis. It also plays a role in sexual function, regulating the onset of puberty (as an essential molecule for development of the reproductive system axes) and in food intake disorders (Bluher and Mantzoros 2015). Levels of leptin also increase in women suffering from premenstrual syndrome (Domonev et al. 2000).

Adiponectin, a protein with 244 amino acids, was discovered in 1995 (Scherer et al. 1995). It is the most abundant product of adipose tissues, and inhibits the proliferation and migration of smooth muscle cells. It protects against the development of atherogenic changes, inhibiting the transformation of macrophages into foam cells. It also increases the oxidation of fatty acids in muscles, lowers plasma levels of glucose, triacylglycerol, and free fatty acids, as well as having anti-inflammatory and anti-apoptotic effects (Nedvídková et al. 2005, Bluher and Mantzoros 2015).

Adipsin is a serine protease that stimulates the transport of glucose for accumulating triglycerides in adipose cells and inhibits lipolysis (Miner 2004). Adipsin (factor D) plays a role in the alternative pathway for complement activation by cleaving factor B. Cook et al. (1985) first described the relationship between adipose tissue and complement factors, finding adipsin expressed in differentiated adipocytes. In another study they demonstrated adipsin secretion in adipocytes and a lowering of levels in rodent obesity models (Cook et al. 1987).

Visfatin (an abbreviation of "visceral fat") was described in 2004 (Fukuhara et al. 2004). This adipokine is mainly produced in visceral fat tissues and only minimally in subcutaneous fat. Its production increases with increasing obesity, or rather with increasing visceral fat. Secretion increases during hypoxia, inflammation, and hyperglycemia, while insulin and somatostatin lead to lower levels. Similarly to insulin, visfatin decreases blood glucose levels, increasing transport to muscle cells. It contributes to lipogenesis and the differentiation of adipocytes in visceral adipose tissue, increasing their capacity to store fat (Adeghate 2008).

Ghrelin was described in 1999 (Kojima et al. 1999). It is a peptide of 28 amino acids, mainly produced in cells of the intestinal tract, mostly in the stomach and in lesser amounts in the intestines and pancreatic epsilon cells. Ghrelin has a significant orexigenic effect, increasing feelings of hunger and appetite (an initiator of eating), lowering feelings of fullness, and reducing sensitivity to gastric distention leading to subsequent overeating. It is thus a critical factor influencing food intake and energy balance (Klok et al. 2007).

Resistin was described in 2001 (Steppan et al. 2001). In humans it is a peptide of 108 amino acids that is mostly produced in immune system cells, particularly in macrophages located in adipose tissue. The main trigger of the secretion of resistin is inflammation, while estrogens and IGF-1 lower resistin levels. Resistin is considered a link between endotoxemia, inflammation, and the onset of insulin resistance. In animal models, this link has been demonstrated conclusively, but in humans the question of resistin function seems to be more complicated (Schwartz and Lazar 2011).

\section{Methods}

We measured changes in steroid hormones, adipokines and food intake-related hormones during the menstrual cycle in healthy women. Twenty-seven women with regular menstrual cycles (cycle length $28 \pm 2$ days) were included in the study. The average age of the women was $31.8 \pm 3.56$, and average BMI 22.9 \pm 2.8 . The women used no hormonal contraceptives or other medicines influencing the production of steroid hormones, and were non-smokers. Before enrollment in the study, all signed informed consent that was approved by the local ethical committee of the Institute of Endocrinology.

Fasting blood samples were taken in the morning between 7 and $8 \mathrm{am}$. The first sampling was done at the start of the menstrual cycle $\left(1^{\text {st }}\right.$ or $2^{\text {nd }}$ day). Subsequent samples were taken at regular intervals every three days, for a total of 10 samples taken during the study.

Each sample was collected in cooled EDTA tubes, centrifuged at $2000 \mathrm{rpm}$ in a refrigerated centrifuge, and stored at $-80^{\circ} \mathrm{C}$. For all samples we measured luteinizing hormone $(\mathrm{LH})$, follicularstimulating hormone (FSH), sex hormone-binding globulin (SHBG), testosterone, dehydroepiandrosterone (DHEA), estradiol, 7 $\alpha$-DHEA, 7 $\beta$-DHEA, 7-oxoDHEA, 17-hydroxyprogesterone (17-OH $\mathrm{P})$, progesterone, cortisol, adrenocorticotropic hormone (ACTH), and a complex of hormones associated with food intake: 
C-peptide, ghrelin, gastric inhibitory polypeptide (GIP), glucagon-like peptide-1 (GLP-1), glucagon, insulin, leptin, resistin, visfatin, adipsin, and adiponectin.

\section{Analytical methods}

Analyses measured by RIA and IRMA

Testosterone was measured by a standard radioimmunoassay (RIA) using antiserum antitestosterone-3-carboxymethyloxim: BSA and testosterone-3-carboxymethyloxim-tyrosylmethyl-ester[125I] as a tracer. Intra-assay and inter-assay coefficients variants were $7.2 \%$ and $10 \%$, respectively, and sensitivity was $0.21 \mathrm{nmol} / \mathrm{l}$.

Commercial RIA kits from Immunotech (Marseilles, France) were used to measure DHEA levels. $7 \alpha$ - and $7 \beta-O H-D H E A$ were measured in plasma by radioimmunoassays using polyclonal rabbit antisera against 7-OH-DHEA-19-(Ocarboxymethyl) oxime conjugates, with bovine serum albumin and radioiodinated homologous derivatives with tyrosine methyl ester as tracers (Lapčík et al. 1998, 1999). Intraand interassay coefficients of variation were $6.7 \%$ and $10.0 \%$ for $7 \alpha-\mathrm{OH}-\mathrm{DHEA}$, and $7.1 \%$ and $10.6 \%$ for 7B-OH-DHEA, respectively; the detection limits were 1.06 and $0.95 \mathrm{pg} /$ tube. The cross-reactivity of the antisera with chemically related steroids present in the material analyzed was as follows. For $7 \alpha-\mathrm{OH}-\mathrm{DHEA}$ antibody: 7ß-OH-DHEA, $1.16 \%$; DHEA, $1.95 \%$; androstenedione, $0.38 \%$; pregnenolone and dihydrotestosterone, $0.04 \%$ each; and testosterone, $0.01 \%$. The cross-reactivity with other hormonal steroids such as cortisol, estradiol, and progesterone was negligible. For 7ß-OH-DHEA antibody: $7 \alpha$-OH-DHEA (the opposite epimer), $0.28 \%$; DHEA, $0.18 \%$; androstenedione, $0.096 \%$; testosterone, $0.013 \%$; cross-reactivity with other hormonal steroids such as cortisol, estradiol, progesterone and dihydrotestosterone was negligible. 7-oxo-DHEA was determined by the RIA method according to Kazihnitková et al. (2007).

LH and FSH were estimated using IRMA kits from Immunotech (France). SHBG and estradiol were assessed using IRMA kits from Orion (Finland). Cortisol was measured by an RIA kit from Orion (Finland). Progesterone and 17-hydroxyprogesterone was measured using an RIA kit from Immunotech (France).

All immunoassays were processed on a Stratec automatic analyzer (France).
ACTH was measured using ECLIA (electrochemiluminiscence immunoassay) on a Cobas e 411 analyzer, Roche Diagnostics, Mannheim.

Levels in plasma of hormones associated with food intake (c-peptide, ghreline, GIP, GLP, GLP-1, glucagon, insulin, leptin, PAI-1, resistin and visfatin) were measured using magnetic bead-based multiple assays (x-MAP technology, Luminex Corporation). Two kits were used: the 10-plex Bio-Plex Pro Human Diabetes assay and the 2-plex Bio-Plex Pro Human Adiponectin and Adipsin assay (both Bio-Rad Laboratories). Measurements were performed on the BioPlex 200 (BioRad Laboratories). These commercial kits were optimized before use. Incubation time was prolonged from one hour to two hours and dilution of plasma in 10-plex was reduced to $1: 2$, from the recommended 1:3. Evaluation of concentrations of individual analytes was calculated by Five-Parameter Logistic Regression analysis from standard curves.

\section{Statistical analysis}

Since data did not show a normal distribution, they were transformed by Box-Cox transformation. Differences between groups were evaluated using repeated measures analysis of variance (ANOVA), followed by Bonferroni's multiple comparison procedure. The statistical software Statgraphics Centurion XVI from Statpoint Inc. (Warrenton, VA, USA) was used for data transformations, ANOVA, and multiple comparisons.

\section{Results}

In this study, we followed changes in selected steroids and adipokines during the menstrual cycle. For all women, profiles during the menstrual cycle were compared after synchronization to the day of peak LH (set as the day 0 reference point). Gonadotropin, estradiol, and progesterone had the expected trends, and all women underwent ovulation (Fig. 1).

During the MC we found increased levels of testosterone, and 17-hydroxyprogesterone during ovulation (Fig. 2). SHBG gradually increased after ovulation (Fig. 2). Changes in DHEA, $7 \alpha$-DHEA, $7 \beta$ DHEA, and 7-oxoDHEA during the MC were nonsignificant. ACTH did not change during the $\mathrm{MC}$, and cortisol had a non-significant peak during ovulation (Fig. 2). 


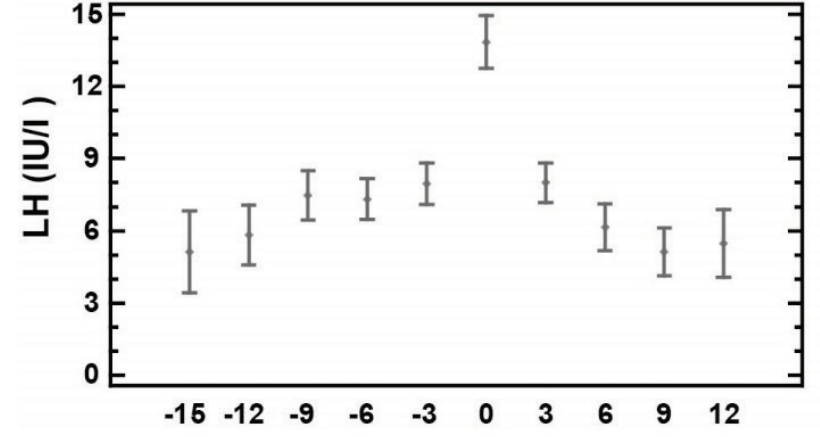

Day of the cycle

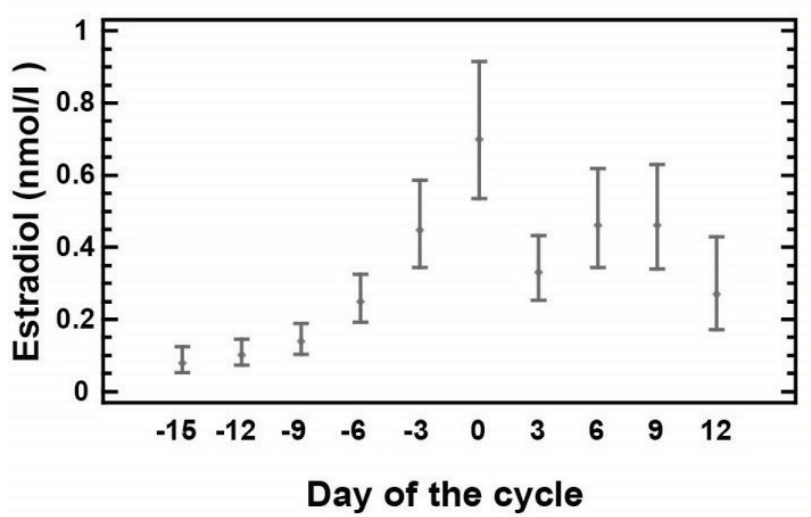

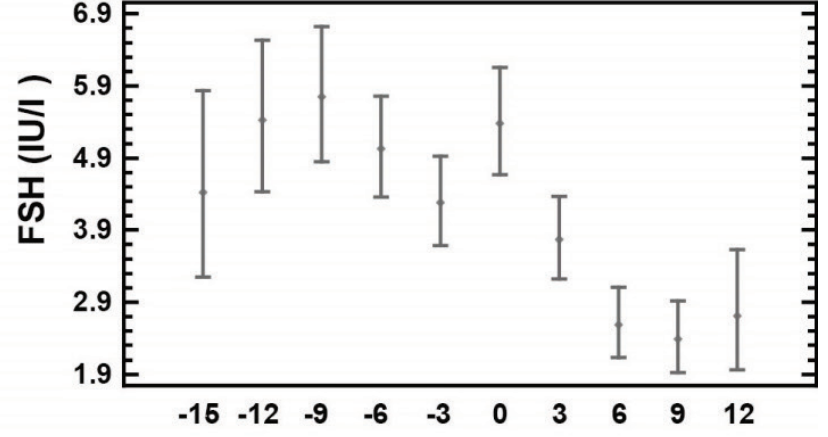

Day of the cycle

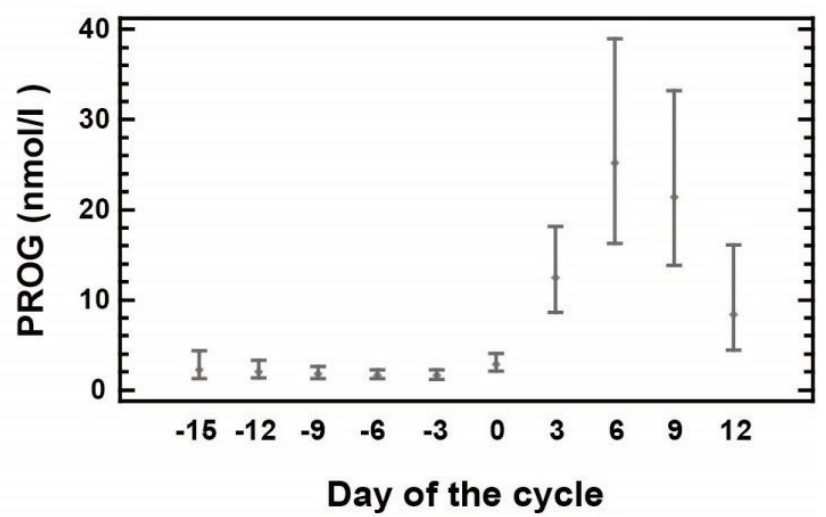

Fig. 1. Profiles of $\mathrm{LH}, \mathrm{FSH}$, progesterone and estradiol during the menstrual cycle.

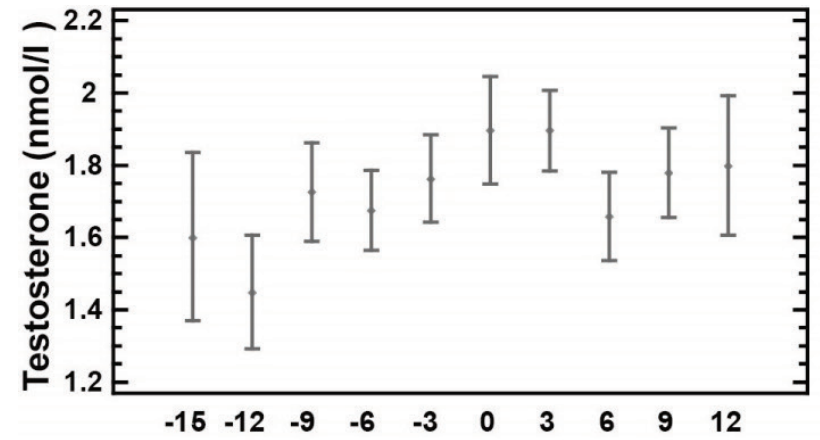

Day of the cycle

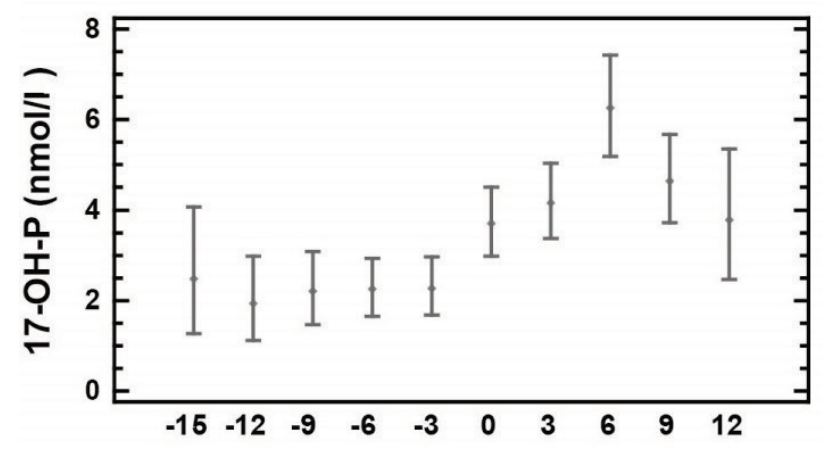

Day of the cycle
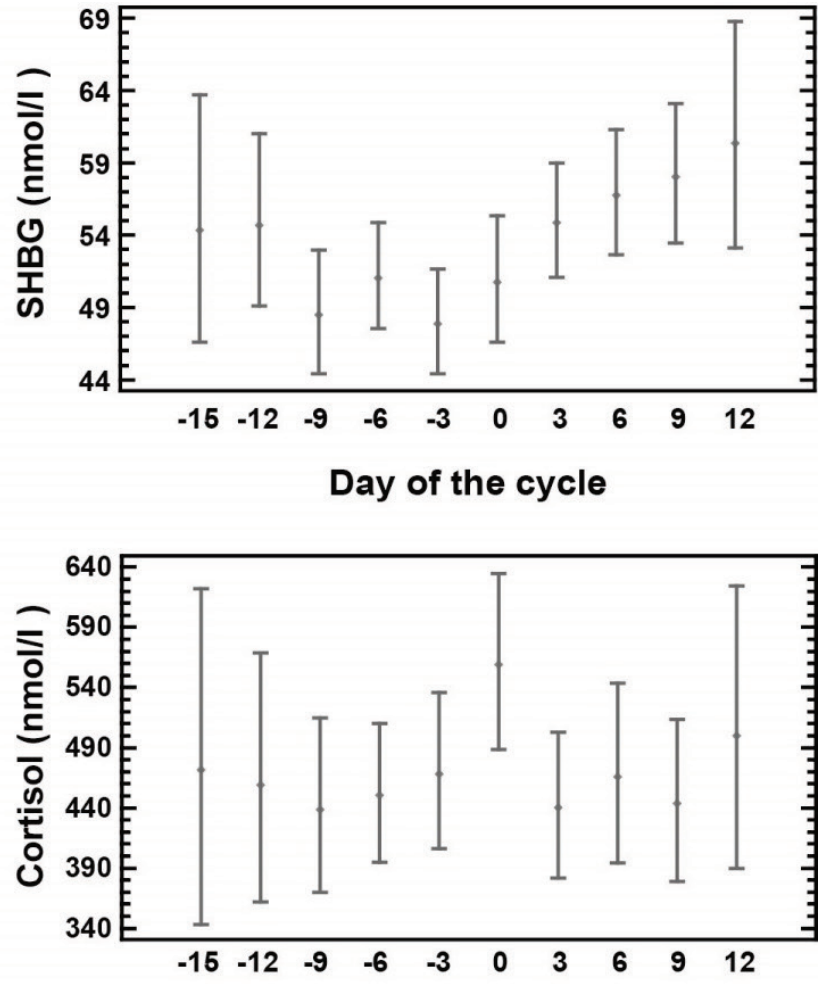

Day of the cycle

Fig. 2. Profiles of testosterone, SHBG, 17-hydroxyprogesterone and cortisol during the menstrual cycle. 

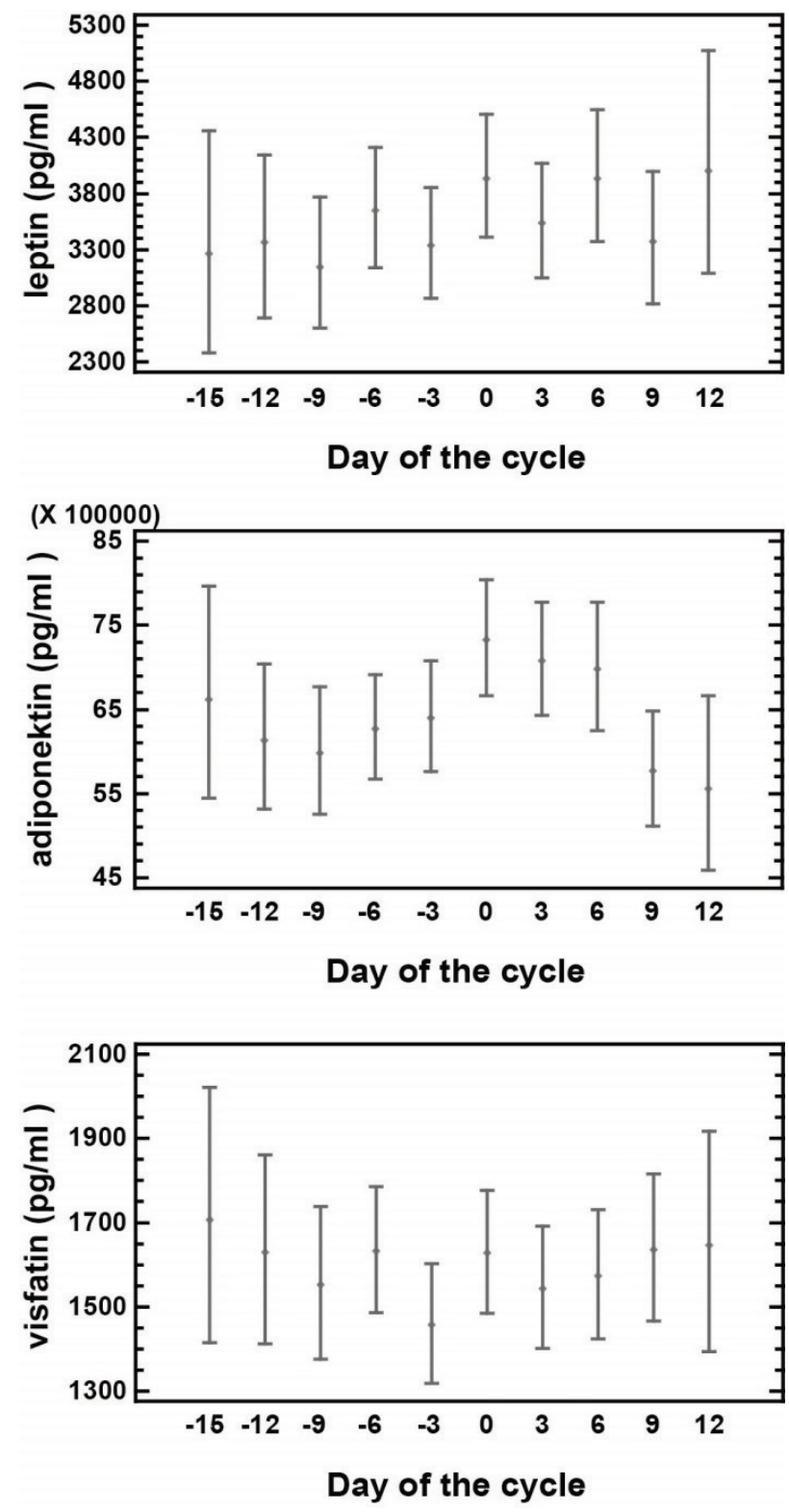

Fig. 3. Profiles of leptin, adiponectin and visfatin during the menstrual cycle.

Leptin showed a non-significant increase during ovulation (Fig. 3). Visfatin levels did not change during the MC (Fig. 3). Levels of adiponectin were significantly higher in the middle of the cycle than during the late luteal phase (Fig. 3).

There was a significant decrease in resistin levels during ovulation, followed by an increase in the latter part of the cycle (Fig. 4). Adipsin showed a notable increase during ovulation, but this increase was not statistically significant (Fig. 4).

Ghrelin did not change during the MC (Fig. 5). Likewise, basal levels of GIP, GLP-1, glucagon, and insulin showed no changed during the MC (Fig. 5).
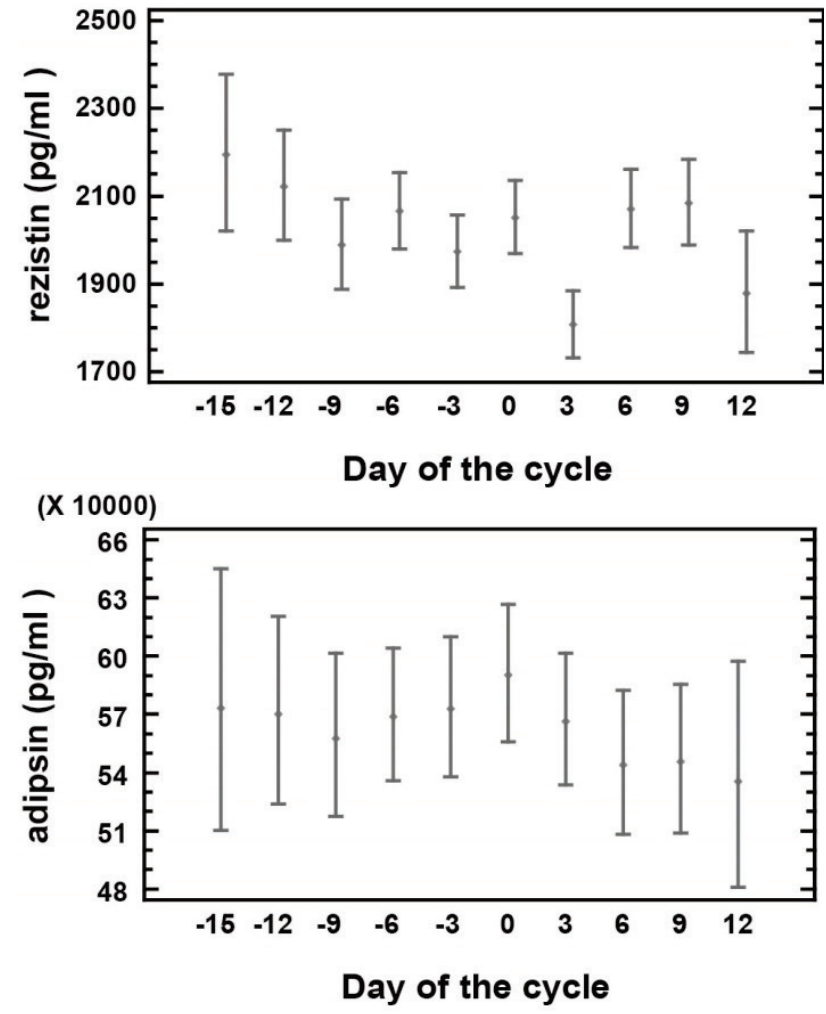

Fig. 4. Profiles of resistin and adipsin during the menstrual cycle.

\section{Discussion}

Our results confirm the generally-accepted findings of higher levels of gonadotropins, estrogen and progesterone at the peak of ovulation. We also found an increase in testosterone, though associated with a decrease in SHBG, so levels of free testosterone increased more than total testosterone. This increase in testosterone during the menstrual cycle is also in line with published results (Bui et al. 2013). Dehydroepiandresterone and its 7-hydroxy and 7-oxy derivatives showed no significant changes. These have been associated with food intake (Stárka et al. 2015), and it is known that in conjunction with 11 betahydroxysteroid dehydrogenase they are important factors in influencing the local activity of glucocorticoids (Hennebert et al. 2009). Cortisol in our study showed an increase during the height of ovulation.

Studies following changes in leptin during the MC have produced different results. Some studies have shown higher leptin levels in the luteal phase (RiadGabriel et al. 1998, Ajala et al. 2013, Asimakopoulos et al. 2009). Mannucci et al. (1998) found lower leptin levels in the follicular phase and demonstrated increases in leptin after giving FSH. Unlu et al. (2014) found higher leptin levels during premenstrual episodes in 
women with premenstrual syndrome. Another study of women with premenstrual syndrome found a decrease in leptin during late luteal phase connected with overeating (Ko et al. 2015). On the other hand, other studies have not found significant changes (Capobianco et al. 2010, Welt et al. 2004, Tucci et al. 2010). Our results show a non-significant tendency of leptin to increase around ovulation.

Changes in ghrelin during the MC have not yet been demonstrated (Dafopoulos et al. 2009, 2010), and in our results indications of a tendency to decrease in the middle of the cycle were not significant. Romani et al. (2012) demonstrated the regulatory effects of ghrelin on the function of luteal cells, which could be influenced by luteal steroidogenesis.

Published data on changes in resistin levels during the MC are inconsistent. Dafopoulos et al. (2009) found no changes, while Asimakopoulos et al. (2009) found higher levels during the luteal phase compared to the follicular phase. In our study, there was a significant decrease in resistin just before ovulation, with subsequent increases in other parts of the luteal phase.

Several studies have found no changes in adiponectin levels during the MC (Asimakopolous et al. 2009, Dafopoulos et al. 2009, Rouen et al. 2010, Saxena et al. 2012). In contrast, we found adiponectin to be significantly higher in the middle of the cycle compared to the late luteal phase, but changes in adipsin were not statistically significant.

Changes to visfatin levels during the MC have not been reported in the literature. In our study, visfatin showed no statistically significant changes.

Brennan et al. (2009) studied changes in emptying of the stomach, increased glycemia, GLP-1 and insulin between the follicular and luteal phases, and demonstrated that stomach emptying is slower and levels of glycemia, insulin, and GLP-1 are lower in the follicular versus the luteal phase. Our results showed no changes in basal levels of GLP-1 or parameters of glucose metabolism during the MC.

Our study demonstrates that in addition to the significant changes in levels of sex hormones - both gonadotropins and steroids - there are also changes in other regulatory factors during the menstrual cycle, including other steroids or adipokines and hormones associated with food intake. These results should help our understanding of the changes in energy metabolism and dietary preferences during the menstrual cycle.
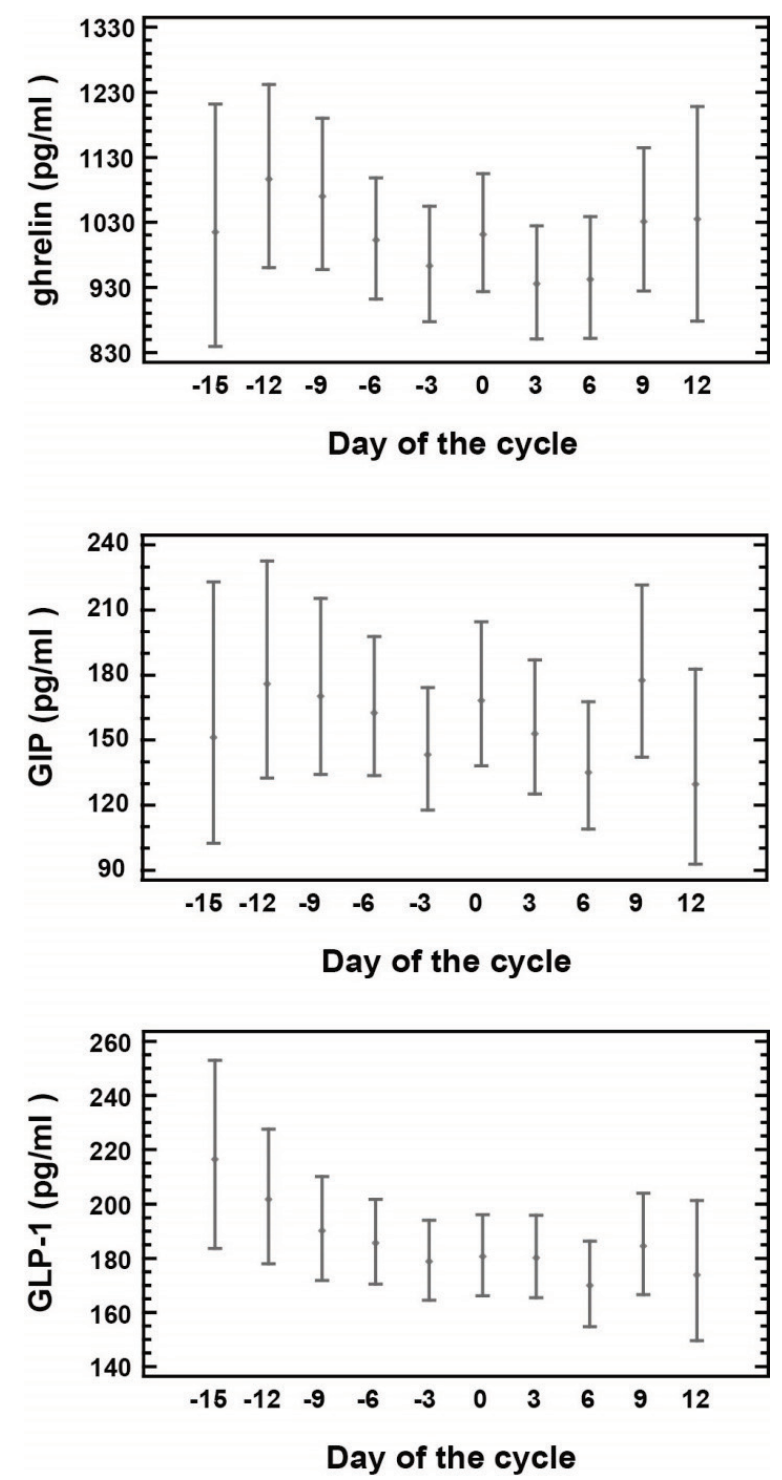

Fig. 5. Profiles of ghrelin, GIP and GLP-1 during the menstrual cycle.

\section{Conclusions}

Cyclical changes in adipokines during the menstrual cycle are not particularly striking, but even so can play a role in the changes in food intake during the menstrual cycle that have been described in the literature. A further important question is the possibility of changes in steroid hormones during the $\mathrm{MC}$ effecting adipokine receptors, which would also contribute to changes in food intake. Various other factors also have impacts on food intake, which could mask the effects of these cyclical changes. Differing leptin levels are characteristic for premenstrual syndrome. Changes in adipokines are typical for disorders of food intake as well as in obesity. In order to precisely discriminate between cyclical 
changes and pathological states, it is necessary to have a better understanding of the pathophysiology of these disorders and the roles of both steroid hormones and adipokines in their development. Detailed descriptions of physiological changes in healthy women are thus of great importance.

\section{Conflict of Interest}

There is no conflict of interest.

\section{Acknowledgements}

The study was supported by grants: IGA MZ CR NT 12340-5 and GAUK 1254314.

\section{References}

ADEGHATE E: Visfatin: structure, function and relation to diabetes mellitus and other dysfunctions. Curr Med Chem 15: 1851-1862, 2008.

AJALA OM, OGUNRO PS, ELUSANMI GF, OGUNYEMI OE, BOLARINDE AA: Changes in serum leptin during phases of menstrual cycle of fertile women: relationship to age groups and fertility. Int J Endocrinol Metab 11: 27-33, 2013.

ASIMAKOPOULOS B, MILOUSIS A, GIOKA T, KABOUROMITI G, GIANISSLIS G, TROUSSA A, SIMOPOULOU M, KATERGARI S, TRIPSIANIS G, NIKOLETTOS N: Serum pattern of circulating adipokines throughout the physiological menstrual cycle. Endocr $J$ 56: 425-433, 2009.

BLÜHER M, MANTZOROS CS: From leptin to other adipokines in health and disease: facts and expectations at the beginning of the 21st century. Metabolism 64: 131-145, 2015.

BRENNAN IM, FELTRIN KL, NAIR NS, HAUSKEN T, LITTLE TJ, GENTILCORE D, WISHART JM, JONES KL, HOROWITZ M, FEINLE-BISSET C: Effects of the phases of the menstrual cycle on gastric emptying, glycemia, plasma GLP-1 and insulin, and energy intake in healthy lean women. Am J Physiol Gastrointest Liver Physiol 297: G602-G610, 2009.

BUI HN, SLUSS PM, BLINCKO S, KNOL DL, BLANKENSTEIN MA, HEIJBOER AC: Dynamics of serum testosterone during the menstrual cycle evaluated by daily measurements with an ID-LC-MS/MS method and a 2nd generation automated immunoassay. Steroids 78: 96-101, 2013.

CAPOBIANCO G, DE MURO P, CHERCHI GM, FORMATO M, LEPEDDA AJ, CIGLIANO A, ZINELLU E, DESSOLE F, GORDINI L, DESSOLE S: Plasma levels of C-reactive protein, leptin and glycosaminoglycans during spontaneous menstrual cycle: differences between ovulatory and anovulatory cycles. Arch Gynecol Obstet 282: 207-213, 2010.

COOK KS, GROVES DL, MIN HY, SPIEGELMAN BM: A developmentally regulated mRNA from 3 T3 adipocytes encodes a novel serine protease homologue. Proc Natl Acad Sci U S A 82: 6480-6484, 1985.

COOK KS, MIN HY, JOHNSON D, CHAPLINSKY RJ, FLIER JS, HUNT CR, SPIEGELMAN BM: Adipsin: a circulating serine protease homolog secreted by adipose tissue and sciatic nerve. Science 237: 402-405, 1987.

DAFOPOULOS K, SOURLAS D, KALLITSARIS A, POURNARAS S, MESSINIS IE: Blood ghrelin, resistin, and adiponectin concentrations during the normal menstrual cycle. Fertil Steril 92: 1389-1394, 2009.

DAFOPOULOS K, CHALVATZAS N, KOSMAS G, KALLITSARIS A, POURNARAS S, MESSINIS IE: The effect of estrogens on plasma ghrelin concentrations in women. J Endocrinol Invest 33: 109-112, 2010.

DAVIDSEN L, VISTISEN B, ASTRUP A: Impact of the menstrual cycle on determinants of energy balance: a putative role in weight loss attempts. Int J Obes 31: 1777-1785, 2007.

FLIER JS: The adipocyte: storage depot or node on the energy information superhighway? Cell 80: 15-18, 1995.

FUKUHARA A, MATSUDA M, NISHIZAWA M, SEGAWA K, TANAKA M, KISHIMOTO K, MATSUKI Y, MURAKAMI M, ICHISAKA T, MURAKAMI H, WATANABE E, TAKAGI T, AKIYOSHI M, OHTSUBO T, KIHARA S, YAMASHITA S, MAKISHIMA M, FUNAHASHI T, YAMANAKA S, HIRAMATSU R, MATSUZAWA Y, SHIMOMURA I: Visfatin: a protein secreted by visceral fat that mimics the effects of insulin. Science 307: 426-430, 2005.

HENNEBERT O, MONTES M, FAVRE-REGUILLON A, CHERMETTE H, FERROUD C, MORFIN R: Epimerase activity of the human 11 beta-hydroxysteroid dehydrogenase type 1 on 7-hydroxylated C19-steroids. $J$ Steroid Biochem Mol Biol 114: 57-63, 2009. 
KAZIHNITKOVÁ H, ZAMRAZILOVÁ L, HILL M, LAPČÍK O, POUZAR V, HAMPL R: A novel radioimmunoassay of 7-oxo-DHEA and its physiological levels. Steroids 72: 342-350, 2007.

KO CH, YEN CF, LONG CY, KUO YT, CHEN CS, YEN JY: The late-luteal leptin level, caloric intake and eating behaviors among women with premenstrual dysphoric disorder. Psychoneuroendocrinology 56: 52-61, 2015.

KLOK MD, JAKOBSDOTTIR S, DRENT ML: The role of leptin and ghrelin in the regulation of food intake and body weight in humans: a review. Obes Rev 8: 21-34, 2007.

KOJIMA M, HOSODA H, DATE Y, NAKAZATO M, MATSUO H, KANGAWA K: Ghrelin is a growth-hormonereleasing acylated peptide from stomach. Nature 402: 656-660, 1999.

LAPČÍK O, HAMPL R, HILL M, BIČÍKOVÁ M, STÁRKA L: Immunoassay of 7-hydroxysteroids: 1. Radioimmunoassay of 7ß-hydroxy-dehydroepiandrosterone. J Steroid Biochem Mol Biol 67: 439-445, 1998.

LAPČÍK O, HAMPL R, HILL M, STÁRKA L: Immunoassay of 7-hydroxysteroids: 2. Radioimmunoassay of 7 $\alpha$ hydroxy-dehydroepiandrosterone. J Steroid Biochem Mol Biol 71: 231-237, 1999.

MANNUCCI E, OGNIBENE A, BECORPI A, CREMASCO F, PELLEGRINI S, OTTANELLI S, RIZZELLO SM, MASSI G, MESSERI G, ROTELLA CM: Relationship between leptin and oestrogens in healthy women. Eur J Endocrinol 139: 198-201, 1998.

MCNEIL J, DOUCET É: Possible factors for altered energy balance across the menstrual cycle: a closer look at the severity of PMS, reward driven behaviors and leptin variations. Eur J Obstet Gynecol Reprod Biol 163: 5-10, 2012.

MINER JL: The adipocyte as an endocrine cell. J Anim Sci 82: 935-941, 2004.

NEDVÍDKOVÁ J, SMITKA K, KOPSKÝ V, HAINER V: Adiponectin, an adipocyte-derived protein. Physiol Res 54: 133-140, 2005.

RIAD-GABRIEL MG, JINAGOUDA SD, SHARMA A, BOYADJIAN R, SAAD MF: Changes in plasma leptin during the menstrual cycle. Eur J Endocrinol 139: 528-531, 1998.

ROMANI F, LANZONE A, TROPEA A, FAMILIARI A, SCARINCI E, SALI M, DELOGU G, CATINO S, APA R: In vitro effect of unacylated ghrelin and obestatin on human luteal cell function. Fertil Steril 97: 991-996, 2012.

ROUEN PA, LUKACS JL, REAME NE: Adipokine concentrations in nonobese women: a study of reproductive aging, body mass index, and menstrual cycle effects. Biol Res Nurs 12: 54-61, 2010.

SAXENA AR, SEELY EW, GOLDFINE AB: Cardiovascular risk factors and menstrual cycle phase in pre-menopausal women. $J$ Endocrinol Invest 35: 715-719, 2012.

SCHERER PE, WILLIAMS S, FOGLIANO M, BALDINI G, LODISH HF: A novel serum protein similar to C1q, produced exclusively in adipocytes. $J$ Biol Chem 270: 26746-26749, 1995.

SCHWARTZ DR, LAZAR MA: Human resistin: found in translation from mouse to man. Trends Endocrinol Metab 22: 259-265, 2011.

STÁRKA L, RÁCZ B, ŠRÁMKOVÁ M, HILL M, DUŠKOVÁ M: Daily profiles of dehydroepiandrosterone and its hydroxylated metabolites with respect to food intake. Prague Medical Report 116: 40-48, 2015.

STEPPAN CM, BAILEY ST, BHAT S, BROWN EJ, BANERJEE RR, WRIGHT CM, PATEL HR, AHIMA RS, LAZAR MA: The hormone resistin links obesity to diabetes. Nature 409: 307-312, 2001.

TUCCI SA, MURPHY LE, BOYLAND EJ, DYE L, HALFORD JC: Oral contraceptive effects on food choice during the follicular and luteal phases of the menstrual cycle. A laboratory based study. Appetite 55: 388-392, 2010.

UNLU BS, KOKEN G, CELIK F, MERT N, YILDIZ Y, KOCA B, YILMAZER M: In contrast to leptin, serum concentrations of ghrelin are not related to premenstrual syndrome. Eur Rev Med Pharmacol Sci 18: 30103015, 2014.

WELT CK, CHAN JL, BULLEN J, MURPHY R, SMITH P, DEPAOLI AM, KARALIS A, MANTZOROS CS: Recombinant human leptin in women with hypothalamic amenorrhea. $N$ Engl J Med 351: 987-997, 2004.

ZHANG Y, PROENCA R, MAFFEI M, BARONE M, LEOPOLD L, FRIEDMAN JM: Positional cloning of the mouse obese gene and its human homologue. Nature 372: 425-432, 1994. 